\title{
How Do Kindergarteners Express Their Mathematics Understanding?
}

\author{
Kyoko Johns \\ Department of Curriculum and Instruction, Jacksonville State University, USA
}

Copyright (C) 2015 by authors, all rights reserved. Authors agree that this article remains permanently open access under the terms of the Creative Commons Attribution License 4.0 International License

\begin{abstract}
This article describes how kindergarten students represent their understanding of mathematical knowledge. The study examines the students' use of oral expressions, drawings, written language, and gestures when communicating mathematically with their classmates and teacher.
\end{abstract}

Keywords Mathematics, Representations, Kindergarten

\section{Introduction}

Young children are capable of solving mathematical problems even before they enter formal school settings. They count objects in their environment and share things with their families and peers daily. There are many occasions where young children are challenged to solve problems such as sharing their snack and dividing toys and food with their siblings and friends. By interacting with others in their community, children learn to communicate and express their mathematical thoughts and knowledge through a variety of ways.

According to the Standards produced by the National Council of Teachers of Mathematics (NCTM) [14], the world's largest organization with more than 80,000 members that are concerned about mathematics education across the US and Canada, and internationally and the Common Core State Standards (CCSS) [2] which are an US initiative developed by the National Governors Association (NGA) and the Council of Chief State School Officers (CCSSO), representation is regarded as an important topic of the mathematics curriculum and an essential aspect for mathematical competence. Both NCTM and CCSS seek to provide mathematics standards that are consistent across the US based on best practices and research $[2,14]$. In order to become mathematically literate and to be able to function in the 21 st century as a productive citizen, students must be able to represent and interpret mathematical ideas and concepts. Much research has been conducted on the functions of representation for older students in the past.
Studies have indicated the importance on focusing on students' thought process rather than end products $[4,11,17$, 18 , but a very few studies have focused on young students and their use of representations. There is a great need to investigate the use of representation in the primary grade settings. The research question "How do kindergarten students express their mathematical understanding?" guided this inquiry. The following section describes literature relevant to the use of mathematical representation in primary classrooms. It is organized into three sections: (1) the use of representation by young children, (2) the role of teachers in young children's mathematics classrooms, and (3) the function of representation in mathematics lessons. Issues regarding future research and the use of representation in primary classroom and its benefits are discussed.

\section{Review of Literature}

\subsection{The Use of Representation by Young Children}

Representation is a part of the process of construction of knowledge, which can be performed either by sharing the ideas with others or individually [2, 14]. According to previous studies based on Piaget's constructivist theory, there are three kinds of knowledge: physical knowledge, social knowledge, and logico-mathematical knowledge. Physical knowledge is the "knowledge of objects in external reality;" social knowledge is the "knowledge of conventions;" and logico-mathematical knowledge consists of "mental relationship, and the ultimate source of these relationships is the human mind" [9-11]. Constructivists emphasize that children construct knowledge by interacting with their environment and creating meaningful connections between new information and their surroundings. Their knowledge is built upon their prior knowledge and experiences. Representation is the way in which young children express their interpretation and understanding of mathematics concepts using their oral and written language [9 - 11]. The use of multiple representations in a classroom is recommended by the CCSS [2] and NCTM standards 
[14].

Kamii [9-11] concentrated on working with young children based on constructivist theory. Her work produced information concerning children's social and intellectual development. Kamii was critical of traditional practices of teaching mathematics in primary classrooms and raised the question of teacher-centered activities and the use of worksheets. Characteristically, her studies examined how young children develop their mathematical knowledge and how teachers support and facilitate their learning. Kamii presented a strong argument that teachers train children to become passive learners by using worksheets and demanding "one right answer" rather than encouraging them to actively participate in their learning. The studies also pointed out that children respect the rules they create and increase their mathematical achievement when teachers expect more from them by challenging their intellect.

The ideas expressed by Kamii lead to a broader conceptualization of children's abilities to utilize and master mathematical concepts. The study of 60 Japanese children ages three to seven years revealed the relationship between their levels of abstraction and their levels of representation [12]. The researchers interviewed children to investigate their abilities to represent a group of objects. The results suggested that children's construction of number concepts were closely related to their levels of abstraction. For example, if a child sees a group of five objects and does not mentally connect them with a number five, that child is not ready to make one-to-one correspondence and can only describe the objects as "bunch", which is considered a lower level of representation. As children develop their one-to-one correspondence skills and number concepts, they can represent these abstract concepts using shapes and symbols accurately.

Young children use representations in their mathematics classroom in so many ways. Woleck [18] studied the ways first graders make use of their drawings to convey their mathematical understanding. The study found children's drawings served as many learning tools for them to explore, investigate, debate, refine, and confirm one's mathematical understanding. There was a strong link between children's oral language development and the use of the pictorial representations. According to Kamii $[9,10]$ and Woleck [18], children are able to engage in abstraction when they move from using pictures to symbols in order to communicate their mathematical ideas and knowledge. Piaget emphasizes that children construct knowledge from within, not by internalizing from the environment $[9,10]$. Studies have stressed that children learn best by exploring and investigating their surroundings and interacting with others in a supportive environment where they are not afraid of taking risks [9-11,13,18].

There are many strategies that encourage and facilitate young children's use of representation in mathematics classroom. Whitin and Whitin [17] conducted a study on the use of children's literature to guide students' mathematical representations. After involving the children in several counting activities using children's literature, they were asked to create visual representations of those experiences. The results indicated that children use a variety of strategies to explain their thinking process and the talk that surrounds this experience enriches their mathematical understanding. The study has suggested that if children are to appreciate the traditional mathematical symbols, they need an opportunity to create such symbols themselves preceding the formal introduction to them [17].

Earlier studies have affirmed the fact that young children do and can use representation when communicating mathematically. These research findings also support Piaget's theory on how young children acquire their knowledge. It is only recently that researchers have begun to systematically examine the effect of the role teachers play in teaching mathematics and the function of representation in mathematics classrooms. One of the central questions of the current studies is the role of teachers in teaching mathematics concepts and skills in young children's mathematics classroom.

\subsection{The Role of Teachers in Young Children's Mathematics Classrooms}

The CCSS [2] and NCTM standards [14] emphasize the importance of the use of concrete, pictorial, and symbolic representation to facilitate student mathematics learning. Previous studies have revealed the roles teachers play in teaching representation in mathematics classroom in recent years. Flevares and Perry [6] conducted a study on how three first-grade teachers incorporated nonspoken representations such as gestures, pictures, objects, and writing during mathematics lessons in their classrooms over 3 years. This study indicated that teachers used nonspoken representations along with verbal instructions to aid student learning. The use of nonspoken representations "supplies an essential but incomplete depiction of classroom communication" (p.343). The study revealed that those teachers used gestures the most during mathematical lessons as a spontaneous communication tool. Researchers conclude that the modeling of the use of representation by classroom teachers encourages children to acquire effective representation skills.

According to McClain and Cobb [13], teachers need to become proactive in leading students in a right direction when teaching mathematics. They conducted an experiment to analyze one teacher's attempt to reorganize her first grade classroom while learning what it means to teach mathematics to young children. The study revealed that the students constructed their disposition toward mathematics with the teacher's guidance and created the learning environment with rules of their own by communicating with each other and the teacher and debating what rules were allowed in this mathematics classroom. Effective mathematics teachers can provide opportunities for students to become autonomous in their learning by establishing 
sociomathematical norms that encourage communication among students and teachers $[9,11,13,19]$. This can be accomplished by creating a learning environment in which students feel secure and are able to construct their own knowledge without the fear of being judged $[9-11,19]$ and by offering a variety of learning settings in classrooms $[3,8$, $13,15]$.

Studies indicate that social interactions between students and a teacher can often facilitate and enhance student learning by providing opportunities for students to reflect on their ideas and thoughts and to take others' views into considerations, facilitating their cognitive development $[16$, 19]. Weigel [16] found that the use of cooperative learning groups in a kindergarten class during the mathematics lesson has a positive impact on student progress in counting schemes. Two kindergarten students, working as a pair in the study, developed a relationship in which they shared their ideas, reflected on each other's thoughts, and debated on the best possible way to come to mutual conclusions. These paired students were able to accomplish more than others who worked under different grouping situations.

Many researchers have emphasized that student learning is maximized when students are engaged in a meaningful mathematics learning context that relates to their needs and concerns and they become independent and confident learners [3, 8-11, 13, 18, 19 ]. Henningsen and Stein [8] conducted a study in which they observed interactions between three classroom teachers and their students to investigate what mathematical tasks maintained students' attention and interest. The researchers identified 58 tasks that encouraged students' mathematical behaviors during the study. The study concluded that supportive actions by teachers are one of the main factors associated with high student engagement during mathematics along with the appropriateness of the task for the students. The results of the study suggested that appropriate instructional planning by the teacher played an important role in maintaining students' engagement during mathematics lessons. It is evident that the teacher and the social norm within a classroom have a great impact on the development of the students' attitude toward mathematics.

Yackel and Cobb's [13] study has established and reported the significance of the classroom teachers' beliefs and values along with their mathematical knowledge and understanding play in shaping students' perceptions toward mathematics. In their study, the researchers collaborated with second and third grade teachers in an attempt to examine the qualities existing in an inquiry based classroom where teachers strive to guide students become autonomous in mathematics. The study gave a description of interactions between teachers and students while they engaged in establishing sociomathematical norms in their classroom by debating with one another. The results of the study clarified the point that the sociomathematical norm was not introduced from the outside, but was created by the teacher and the students within the classroom.

A basic assumption throughout this analysis makes a convincing case that the teacher plays the central role in shaping students' attitudes and perceptions toward mathematics. It is critical that classroom teachers become knowledgeable in mathematics, the functions of different aspects of mathematics, and children's learning process in order to support their mathematical development.

\subsection{The Function of Representation in Mathematics Lessons}

Communication is important in developing mathematical understanding. Students create their own knowledge and develop mathematical meanings as they learn to explain and justify their thinking to others $[6,9,11,17,18]$. As they learn to speak mathematical language, they transform their thinking of mathematical concepts $[9,11,17,18]$. Children first begin to speak about their thoughts in ordinary language. When they are actively involved both physically and mentally in well-coordinated mathematical activities in a developmentally appropriate setting, they can make connections from their ordinary language to mathematical language. Students are more likely to master mathematical concepts and skills when they make the personal connections between what is being taught and their prior knowledge $[9,11,17,18]$.

More attention is being devoted to children's thinking and learning processes to evaluate the current practice of teaching mathematics. English [3] provided a detailed analysis of the problem-posing abilities of third grade students in her study. The children in the study were asked to create their own addition and subtraction story problems verbally after seeing a card with a number problem or a picture. The results of the study called attention to the limited range of children's ability to pose problems in those settings. The study arrived at the conclusion that there was a need "to develop children's problem-solving and problem-posing skills in dealing with operational situations" (Discussion section, 12). The study suggested that teachers could deepen their understanding of how students learn and incorporate this information to guide and enhance student learning by focusing on students' problem solving process. In order for students to communicate mathematically in a classroom, there has to be an open environment within that classroom for them to feel safe and confident.

Yackel and Cobb's [19] study analyzed the social norms created in mathematics classrooms. Their study concluded that in an inquiry based mathematics classroom, teachers create an environment in which students express their mathematical thoughts and ideas, discuss and debate with others, and construct their own meanings of mathematics. The study presents a strong argument that "the teacher plays a central role in establishing the mathematical quality of the classroom environment and in establishing norms for mathematical aspects of students' activity" (Significance section, 6). In such classrooms, both teachers and students pose mathematical problems to reflect and clarify their 
understanding and prior knowledge, thus making students responsible for their own learning $[9,19]$.

Previous studies have indicated that releasing more responsibility onto students in mathematics classrooms, rather than having teachers dispense all the information, and establishing sociomathematical norms in which a teacher and his or her students contribute equally can lead students to become autonomous in mathematics [9-11, 19]. According to Kamii's studies which are based on Piaget's cognitive developmental theory, guiding students to become autonomous in mathematics should be the ultimate goal for classroom teachers.

The results of studies indicate that the use of multiple representation help children in primary classrooms understand mathematical ideas and concepts and refine their mathematical knowledge. Currently, there is a strong emphasis on the use of multiple representations in a classroom and the use of drawings as an effective mathematics instructional tool $[2,14]$. Teachers can gain a wealth of information on how children learn and what they know about mathematics from observing children's drawings and by paying close attention to their conversation and explanation $[9,11,14,17,18]$.

The educational implication of this theory is that the use of multiple representations in a classroom is beneficial for both students and teachers as stated in the CCSS [2] and NCTM standards [14]. A significantly high proportion of the studies in the field is concerned with older students and their use of representation. There is a great need for more in-depth research on the use of multiple representations in primary mathematics classroom along with more professional development opportunities for teachers of young students to incorporate representations in their lessons. It is imperative that primary classroom teachers become knowledgeable about how young students learn and how best to facilitate student learning $[5,9,11]$.

So what are the ways children represent their mathematical understanding? In the review of the literature, interest has been generated in identifying various methods young children use to represent their mathematical knowledge and understanding and the ways for a classroom teacher to utilize this information to maximize student learning. This investigation represents an attempt to address the use of representation by kindergarten students to describe the current practice in one public kindergarten classroom.

\section{Methods}

\subsection{Participants and Setting}

The participants in this study were 18 predominantly middle-class kindergarten students who attended a public elementary school where kindergarten through fifth grades units were located on one campus. This was a convenience sample. There were approximately 800 students, of which
$40 \%$ qualified for the free or reduced lunch program, in a rural town in the Southern United States. The school served 80\% Caucasian, 18\% African American and 2\% Hispanic and Asian students.

The students in this kindergarten class were aged 5 to 7 years. Sixteen students were Caucasians and two were African-Americans. Most of students came from the lower to middle socioeconomic homes. Many parents were employed by nearby factories or local businesses in this rural community. Parent Teacher Organization (PTO) members actively organized many events to raise funds for the school and were very successful in many of them, but most of the parents did not attend regular PTO meetings and programs, which was usually held once a month in the evening. Some parents did not have any means of reliable transportation and/or home phone limiting their active involvement and contact with the school.

\subsection{Data Collection}

Data were collected for this study in four ways in order to enhance the validity of the research findings. Data collection methods included observation/audiotaping, informal interviews, children's journals/conferences, and field notes during the three-week period in January through February. The primary investigator was a public school teacher who conducted this study in her kindergarten class.

\section{Observation/Audiotaping}

Observation/audiotaping were conducted throughout the normal school day in which students engaged in a variety of mathematics activities individually, in small groups, and in a whole class setting. Individual and small group mathematics activities included the writer's workshop, center time, and some of the math lessons. Calendar time and math lessons were conducted in a whole group setting every day. The primary investigator used audiotapes to record interactions between students and her to be transcribed later for analysis. The teacher kept a journal of field notes to record any mathematics-related interactions between students and her observed during the day.

Center time in this classroom consisted of: 1) computer centers that provided a variety of educational games; 2) theme centers such as Halloween center in October and Snowman center in January, included several books, folder games and card games that were consistent with skills and concepts covered during language and mathematics lessons, and were accompanied by theme puppets, and other manipulative materials; 3) building center which included blocks, Legos, books on building and heavy equipment, writing materials, and games; 4) home center which consisted of cooking materials, dolls, telephones, memo pads, recipe books, and writing materials; 5) overhead center which provided interactive language, science, and math games along with other seasonal centers.

Students were divided into four heterogeneous groups of four to five students. Each group stayed in a particular 
center for the length of 20-30 minutes during the literacy center time where they collaborated and worked together as a team or, they might choose to work individually. There were two computers for students to use in the computer center. Each student might also choose to read books in the reading center during the literacy center time if he/she decided to do so.

\section{Informal Interviews}

All interviews were informal. Data was collected during the writer's workshop, in which students made an entry of their choice in their journal and during center time, where students participated in different learning activities with minimal adult assistance. Students engaged in the writer's workshop 10-20 minutes daily and spent 20-30 minutes in centers daily. Informal interviews followed interactions between students and the teacher to clarify a student's mathematical thinking. Informal interviews consisted of casual conversations among the students and the teacher during the course of the school day. Gall, Borg, and Gall [7] stated the following:

The informal conversational interview "relies entirely on the spontaneous generation of questions in a natural interaction, typically one that occurs as part of ongoing participant observation fieldwork (the researcher observes and interacts closely enough with individuals to establish a meaningful identity within their group; however, the researcher does not engage in activities that are at the core of the group's identity). Because the conversation appears natural, the research participants may not even realize that they are being interviewed. (p.309)

The teacher circulated through the room during center time to spend time in each center talking with students and asking questions about what is happening at a certain center. The focus of the informal interviews was the students' responses to their peers' and the teacher's comments and questions while they were performing mathematical tasks in those settings.

The contextual nature of the questions was designed to gain an in-depth understanding of students' thoughts and perceptions regarding mathematics concepts such as numbers and comparison. The questions were phrased to clarify students' actions and comments in order to determine their mathematical thinking and learning process.

\section{Children's Journals/Conferences}

During the writer's workshop, students made an entry in their journal by drawing a picture with crayons and markers and write something about that picture by using letters and words they know. The students had been exposed to interactive and shared writing experiences with the teacher everyday where a teacher demonstrated conventional reading and writing strategies with the whole class. Each student was to use these strategies in an attempt to write a story or label the picture at their developmentally appropriate level.

After completing their entries, students had individual conferences with the teacher to discuss what they had written in their journal. The teacher utilized individual conferences to assess students' progress and evaluate needs and interests of each student. The writer's workshop allowed the teacher to spend time with each student in order to gain in-depth information on how students expressed their mathematics understanding using their drawing and writing.

\section{Field Notes}

After each interview and observation, the teacher's thoughts and reflections were recorded in a journal of field notes. Although much of the data included interactions between students and the teacher in above settings, field notes were not limited to those situations.

A descriptive analysis was used to determine students' mathematical representations. Each audiotaped lesson and activity was transcribed for further analysis. Informal interview questions addressed students' views, beliefs, attitudes, and thoughts about doing mathematics. For example, the teacher might ask students to explain how they divided blocks used to build things in the block center among themselves or why they chose to do it in a certain way. The teacher might ask a student to explain more about what he/she had said during a certain mathematics activity. The interviews were intended to clarify students' thought and problem solving process in order for the investigator to better understand their learning process and how they expressed their mathematical understanding. Pseudonyms were used in this paper to protect students' privacy.

\section{Results}

\section{Analysis of the Data}

Qualitative collection of data to answer the research question "How do kindergarten students express their mathematical understanding?" involved observation/audiotaping, informal interviews, collecting student samples, and field notes during the three-week period in January through February by the primary investigator who was a kindergarten teacher. The data collected over the three-week period consisted of over 30 hours of audiotapes, 60 informal interviews, and 70 conferences. All of the audiotapes were transcribed verbatim by the principal investigator. In addition, there were 30 field notes and reflections. The data consisted of over 550 pages of transcriptions, field notes, and other documents from informal interviews and conferences.

The analytic process included repeated sorting, codings, and comparisons that characterize the mathematics-related topics. Coding process was based on the open coding procedure that examined minute sections of text to identify categories and properties of words and phrases.

\section{Observation/Audiotaping}

Observation was conducted throughout the day and 
audiotaping was conducted during center time and calendar time along with whole group mathematics lessons. During center time, students discussed many mathematics-related topics with their peers and the teacher. All comments were collapsed into 12 major categories: (1) numerals; (2) graph; (3) measurement; (4) shapes; (5) spatial sense; (6) patterns; (7) sorting; (8) addition; (9) subtraction; (10) weight; (11) date/time; and (12) money.

These following concepts were mentioned in some way during observations and audiotaping during each of the 20 days of the study: (1) numerals; (2) measurement; (3) patterns; (4) date/time; and (5) money. In this kindergarten classroom, the use of calendar and creating patterns on their calendar, recording the date in children's journal, and handling money for their lunch and snack was a part of their daily routine. Thus, these concepts were mentioned from day one. Least frequent mentions were substations and weight and others were mentioned with a middle range of frequency. The results in the study were comprehensive and diverse in terms of mathematics concepts.

Students used reasoning, problem solving, and critical thinking skills to analyze data. They communicated their analysis with their peers and the teacher orally and sometimes on paper.

Students discussed concepts of more and less while they had lunch and compared what others were eating and shared their snack. One day during lunch, students compared their plates and teachers' plates as they sat together at the table. Then they came to a conclusion that since teachers' bodies were larger, they needed more food than students did. Students used their reasoning and critical thinking skills as they debated and discussed this issue that was very important to them.

They divided materials in centers while they played together to make it "fair". As Savannah played in the kitchen center with Jill and Taylor, they discussed what they were going to have for supper by dividing up toy foods in the center. They decided that they would pass one food item to each person until it was gone to make sure that everyone had the same amount of food. These were examples of problem solving at the center requiring the use of reasoning skill.

Students talked about numbers, shapes, colors, patterns, dates, time, and weather graph on a daily basis. For example, Cortez and Savannah counted how many chicken nuggets they had on their plates, an example of numerals, during lunch one day and compared their results. As Hudson and Alex compared whose fried chicken was bigger, an example of measurement, during another lunchtime, other students started to do the same with a great excitement. Students noticed that the teachers were served with more food on their plates than were the students. They discussed why this was so and concluded that the bigger people needed to eat more food, an example of the children using measurement and spatial concepts. The use of mathematics skills and concepts were a part of students' daily routine in this kindergarten classroom.
The researcher also investigated students' attitudes and views toward mathematics by observing them during various activities and listening to their conversations. The findings were very positive.

One morning after children had been using a ruler to measure a class mascot, an alligator named "Bridgett", for about a week, Cortez came in the classroom with the biggest smile on his face holing a brand new ruler in his hand. He came to the teacher announcing that he had a ruler just like hers. He was very excited about having his own ruler and proud to measure items found in the classroom. Anytime Cortez heard someone talk about length or saw his classmates pick up a ruler to measure during their center or free time, he also got his ruler. His enthusiasm toward mathematics became obvious through his action.

As noted above, the students in this classroom incorporated mathematics concepts into their lunch and center time conversations showing their enthusiasm and excitement toward mathematics. Their views of mathematics at this point seemed very positive according to the results of this study.

Although many children were able to express their understanding of mathematics concepts on paper by writing numbers and drawing pictures, they often relied on their oral language to explain and debate their thinking. They used phrases such as "I did (solved) it like this," "I figured it out this way," and "Look at what I've done!" during many activities. When their peers or the teacher asked them to explain how they completed a specific task, how they came up with an answer, or what they were doing, children often used previous statements along with hand gestures. This made it extremely difficult for the researcher to capture everything that went on in this classroom. The use of videotape might provide more opportunities to observe interactions between children and the teacher in detail to be analyzed in the future study.

The use of audiotape posed another issue in this study. Because this classroom utilized small groups for center time, it was hard to follow many activities that were happening in the classroom at the same time. The students' spontaneous reactions to a specific situation that might reveal their process of thinking and understanding were not captured in the audiotape on many occasions. The noise level of the classroom was very high due to the fact that there were two computers which four children shared while they worked on educational games with sound at most of the time. This made transcribing the tapes very difficult. There would be more opportunities for researchers to collect complete data that would represent interactions between the students and teacher in this classroom with more depth if there were additional researchers or assistants on site. The coding system to identify frequency of different mathematics concepts that were mentioned in this classroom in different situations that the researcher had planned to use did not work well with for this very reason. 


\section{Informal Interviews}

Informal interviews conducted during this study involved clarifying students' comments and actions on various situations that involved mathematics activities by asking specific questions. These questions included: "Are you sure?" "How do you know that's the answer?" "How did you figure that out?" and "Can you think of another way to figure this out?"

One morning while students were working in their centers, Lynn told Taylor that he was not going to be joining her and others in the block center because there were four people in that center. When the teacher asked her why Taylor couldn't play in the block center, she responded "there were more than four people in that center and that only four people could stay in one center and that her and her friends were there first". Lynn used her reasoning skill and the concept of measurement to explain why Taylor had to go to another center.

When Kate couldn't figure out what the date was to record in her journal, Colin and Ann started to help her by suggesting different dates. Then Colin excitedly said that it was "February 9th, 2004!" When the teacher asked Colin how he figured out what the date was, he responded that "it was 6th on Friday and we were out for two days from school." As he explained his reasoning to the teacher, he held up two fingers and pointed to each finger while he counted 7 and 8 . The students used both measurement and time/date concepts as they reasoned out the problem.

\section{Children's Journals/Conferences}

Student samples were collected from their journals and class book making sessions on special occasions. On 100th day of school, students were asked to complete the sentence "If I had $\$ 100$, I would buy __ " and to draw a picture of what they would buy to place in their class book. Alex drew a picture of a bus and a baby and dictated "I would buy a bus and a brother". He also wrote "101\$" on his page. When asked why he wrote "101\$" on his page, he responded excitedly, “I put 101 for $\$ 101$. That means I'm rich!" Hudson drew a hot dog with legs and dictated to the teacher to write "a big hot dog with 100 legs" on his page. He told the teacher that he wanted 100 legs on it (hot dog). When the teacher asked him how he knew that he had 100 legs on his page, he said, "because it's got so many." Elizabeth drew a gingerbread man on her page and wrote "100" next to it. She explained that she drew one (gingerbread man) because there wasn't enough room and that she had put 100 when the teacher asked her what the number " 100 " meant, the uses of concepts of numerals, money, spatial sense, and reasoning. The students' attitudes and perceptions showed excitement in using mathematics.

\section{Field Notes}

The teacher made entries in her field notes each day to reflect on mathematics-related interactions between students and her. Comments in the researcher's field notes indicate that participants in this study used mathematics vocabularies on a daily basis. The mathematics related comments were made from the time children entered the classroom until the time they left for home in the afternoon. Students made comments to each other and to the teacher regarding things of their interest at random. Mathematics related questions were asked regularly in the classroom by both children and the teacher. Class discussions were a central part of this classroom routine. After the discussions, the teacher recorded what went on during each session and reflected in her field notes.

One day during snack time, Robert took out several little pouches of candy to share with his friends. As he handed those pouches to several boys, he told them that he would bring two more pouches for them tomorrow, so they could have one for snack and take one home for later. Lynn, who was sitting close to the boys, said to Robert that he should bring everyone one of the pouches. Robert responded that he did not have enough for everyone. Lynn told him that he needed 18 pouches for everyone in the class, uses of concepts of numerals, one-to-one correspondence, and reasoning skill in order to make her case.

The teacher recorded that students were very interested in the use of ruler since they started to measure Bridgett. Students talked about length and compared different items in the classroom on a daily basis. Hudson and Alex sat by each other during lunch one day and compared the lengths of their fried chicken as they ate. Other students started to do the same when they heard the boys talk about the length of chicken bone.

During lunch, many children discussed volume, numbers, and length as they shared the table with others. One of their favorite things to do when they had apples and oranges for dessert was to count seeds from those fruits. Students gathered apple and orange seeds and compared size, shape, and color. They also talked about how many seeds each child had and compared numbers with others. These seeds became manipulatives for students to add and to subtract as they exchanged seeds with others.

Students were very eager and excited about sharing their mathematical knowledge and understanding with others. They used their oral language to communicate their opinion on many occasions and also utilized written numbers and pictures to express their knowledge and understanding of mathematics.

\section{Results}

The findings from the data regarding a research question "How do kindergarten students express their mathematical understanding?" indicated that the children in this kindergarten classroom expressed their mathematics understanding in a variety of ways and the teacher assessed children's mathematical knowledge and understanding by observing children's actions, conversations, and through questioning. To do this, the teacher used informal interviews, children's journals/conferences, and field notes. The assessment was a regular part of daily routine in this classroom. The teacher used information gathered from 
these assessments to evaluate her own teaching methods and planned for future lessons.

\section{Conclusions and Discussion}

The students in this study successfully utilized oral and written representations to communicate mathematically. Their abilities to problem solve and perform mathematical task in small groups and independently demonstrated the efficiency and confidence that they had learned by actively participating in the Eight Standards for Mathematical Practices established by the Common Core State Standards (CCSS) Initiative on a daily basis. The CCSS Mathematical Practice Standards [1] include the following:

1. Make sense of problems and persevere in solving them;

2. Reason abstractly and quantitatively;

3. Construct viable arguments and critique the reasoning of other.;

4. Model with mathematics;

5. Use appropriate tools strategically;

6. Attend to precision;

7. Look for and make use of structure;

8. Look for and express regularity in repeated reasoning.

The students in this study were asked to think mathematically and critically during learning activities which resulted in deeper understanding of the number system and patterns. The teacher collected information regarding children's progress and thinking processes by posing many questions and observing children. That information was utilized to assess each child in this kindergarten classroom. The alternative assessment methods used in this study provided the teacher with more insight regarding what the children knew than do traditional assessment methods of testing children, since some children might not test as well as they would in these situations for a variety of reasons. This finding confirms that the use of alternative assessment methods provides a deeper insight into children's thought process [11, 19-20].

The questioning strategies used in this classroom provided a rich mathematics learning environment for students. The students were asked to clarify their problem solving processes and strategies on a daily basis. This practice challenged them to reflect on their mathematical thoughts and ideas and led to conceptual understanding. It was obvious that the teacher was aware of how to engage children in mathematics by holding them accountable in many classroom situations. The recognition of this phenomenon raised the possibility that the years of experience and expertise of a teacher could influence the outcome of the study.

The findings of this study confirmed previous research [9 $-11,13,18]$ in that young students could problem solve independently and express their mathematical understanding using oral and written representations. In order for the teachers of young children to assess children's mathematics knowledge and understanding, one has to be knowledgeable in young children's thinking and learning process. Teachers and researchers also need to be aware of the ways in which children communicate so that they can incorporate alternative assessment methods in their daily routine. By understanding how young children learn and communicate, teachers will be able to fully support their mathematics development. It would be interesting to investigate the difference between how the same group of children expresses their mathematics understanding at the beginning of the school and at the end of the school year.

\section{REFERENCES}

[1] Common Core State Standards Initiative. (2011). Common Core State Standards Initiative. Retrieved November 30, 2013, from http://www.corestandards.org

[2] National Governors Association Center for Best Practices \& Council of Chief State School Officers. (2010). Common Core State Standards for Mathematics. Washington, DC: Authors.

[3] English, L. D. (1998). Children's problem posing within formal and informal contexts. Journal for Research in Mathematics Education, 29, 83-107. Retrieved September 17, 2003, from http://web23.epnet.com

[4] Goldin, G., \& Shteingold, N. (2001). Systems of representations and the development of mathematical concepts. In Albert A. Cuoco \& Frances R. Curcio (Eds.), The Role of Representation in School Mathematics (pp.1-23). Reston, VA: National Council of Teachers of Mathematics.

[5] Fraivilling, J. L., Murphy, L. A., \& Fuson, K. C. (1999). Advancing children's mathematical thinking in Everyday Mathematics classrooms. Journal for Research in Mathematics Education, 30, 148-170.

[6] Flevares, L. M., \& Perry, M. (2001). How many do you see? The use of nonspoken representations in first-grade mathematics lessons. Journal of Educational Psychology, 93, 330-345.

[7] Gall, M. D., Borg, W. R., \& Gall, J. P. (1963). Educational Research: An Introduction. White Plains, NY: Longman.

[8] Henningsen, M. \& Stein, M. K. (1997). Mathematical tasks and student cognition: classroom-based factors that support and inhibit high-level mathematical thinking and reasoning. Journal for Research in Mathematics Education, 29, 524-550.

[9] Kamii, C. (1982). Number in Preschool and Kindergarten: Educational Implications of Piaget's Theory. Washington, D.C.: National Association for the Education of Young Children.

[10] Kamii, C. \& Clark F. B. (1994). The six national goals. Phi Delta Kappan, 75, 672-678.

[11] Kamii, C., Kirkland, L., \& Lewis, B. A. (2001). Representation and abstraction in young children's numerical reasoning. In Albert A. Cuoco \& Frances R. Curcio (Eds.), 
The Role of Representation in School Mathematics (pp.24-34). Reston, VA: National Council of Teachers of Mathematics.

[12] Kato, Y., Kamii, C., Ozaki, K., \& Nagahiro, M. (2002). Young children's representations of groups of objects: the relationship between abstraction and representation. Journal for Research in Mathematics Education, 33, 30-45.

[13] McClain, K. \& Cobb, P. (2001). An analysis of development of sociomathematical norms in one first-grade classroom. Journal for Research in Mathematics Education, 32, 235-266.

[14] National Council of Teachers of Mathematics. (2000). Principles and Standards for School Mathematics. Reston, VA: Author.

[15] Senger, E. S. (1997). Student-invented numeration systems: pattern-analysis and mathematical understanding. Journal for Research in Mathematics Education, 97, 139-150.

[16] Weigel, H. G. (1998). Kindergarten students' organization of counting in joint counting tasks and the emergence of cooperation. Journal for Research in Mathematics Education, 29, 202-225.
[17] Whitin, P., \& Whitin, D. (2001). Using literature to invite mathematical representations. In Albert A. Cuoco \& Frances R. Curcio (Eds.), The Role of Representation in School Mathematics (pp.228-237). Reston, VA: National Council of Teachers of Mathematics.

[18] Woleck, K. R. (2001). Listen to their pictures: an investigation of children's mathematical drawings. In Albert A. Cuoco \& Frances R. Curcio (Eds.), The Role of Representation in School Mathematics (pp.215-227). Reston, VA: National Council of Teachers of Mathematics.

[19] Yackel, E. \& Cobb, P. (1996). Sociomathematical norms, argumentation, and autonomy in mathematics. Journal for Research in Mathematics Education, 27(4), 458-477.

[20] Yeatts, C. L., Battista, M. T., Mayberry, S., Thompson, D. \& Zawojewski, J. S. (2004). Navigating through problem solving and reasoning in grade 3. Reston, VA: National Council of Teachers of Mathematics. 